\title{
Negotiating your job plan as a consultant: understanding the basics
}

\author{
Kathy Oxtoby freelance journalist
}

Negotiating job plans can be baffling for those in their first year as a consultant, and sometimes difficult even for those with experience of the process.

The BMA says that developing a job plan involves looking at what work doctors do for the trust, and where and when. ${ }^{1} \mathrm{~A}$ job plan should, it says, include how much time doctors are expected to be available for work; what this work will deliver for the employer, employee, and patients; what resources are necessary for the work to be achieved; and what flexibility there is around these considerations.

It's also important that doctors know what they can do to shape their job plan, and how best to manage the process. "We need to consider the profession's wellbeing, and having clearly defined job plans is part of that," says Alison Wright, a consultant obstetrician and gynaecologist and vice president, UK and global membership, Royal College of Obstetricians and Gynaecologists.

\section{What job planning involves}

As a former clinical director, Grenville Fox has lots of experience of job planning. He is a consultant neonatologist and a member of the Royal College of Paediatrics and Child Health and says that individual doctors need to be involved in job planning. Fox says that from the trust's perspective it's important for a doctor's job plan to fit what the organisation needs them to do and what's best for patients. From the consultants' point of view, he says, the job plan should be "deliverable and within the contractual obligations they have accepted."

Medical royal colleges also work with the BMA and the Academy of Medical Royal Colleges to make sure job plans are appropriate. For example, Wright says that members of the Royal College of Obstetricians and Gynaecologists have their job plans sent to the college for approval. The college has "strict criteria to make the process as transparent as possible," she says. "A key principle is to make sure that a newly appointed consultant has a job plan that enables them to develop professionally, as well as being linked to the departmental objectives."

Consultants starting new jobs need clear guidance, and a clear plan for their departmental job as a whole, says Wright. And, to help get a good outcome, she says an honest dialogue is crucial.

\section{What a job plan should include}

Job plans should list programmed activities, direct clinical care, and "supporting professional activities." Supporting professional activities are defined in the terms and conditions of the 2013 consultant contract, which describes them as "activities that underpin direct clinical care." It adds, "This may include participation in training, medical education, continuing professional development, formal teaching, audit, job planning, appraisal, research, clinical management, and local clinical governance activities." Wright recommends that "there should be a maximum number of programmed activities that are out of hours" and that private practice should also be included in the job plan for transparency.

\section{Managing the annual job plan review}

How you manage your annual job plan review will vary depending on the organisation you work for. "The process may be reasonably automatic if there has been no significant change in your job plan from the preceding year," says Tim Mitchell, a consultant otolaryngology surgeon at University Hospital Southampton and a member of council of the Royal College of Surgeons of England. He says it's "good practice to have a face-to-face discussion and this should occur where there are significant changes in the job plan."

Preparation is essential to get the most out of your job plan, says Mitchell. "Ensure all elements of your working commitments have been included in a discussion around objectives," he says. But there also needs to be "a degree of compromise to reach an agreed outcome," he advises.

Managing a job plan should be straightforward, but for some doctors there may be a problem that makes it difficult to reach an agreement, such as if a consultant says the amount of hours they take to do administration is more than their colleagues. In these cases, Fox says, "it's about rationalising and being fair to everyone." If there are still problems with the job plan, consultants could seek external advice, such as the BMA. Wright says that, in the interests of fairness and transparency, the Royal College of Obstetricians and Gynaecologists 
encourages "a departmental approach to job planning" and that job plans are linked to the objectives of the department as well as the individual. Another must, she believes, is to be clear about the minimum number of supporting professional activities in the job plan "because sometimes trusts may be under pressure to reduce that number."

It may be necessary to have an interim job plan review where there are significant changes in demands on the service, advises
Mitchell. This could include starting a new service, the introduction of new technology, or a situation where it might not be possible to meet objectives because of resource issues.

1 BMA. What are jobs plans? www.bma.org.uk/advice/employment/job-planning/job-planoverview.

Published by the BMJ Publishing Group Limited. For permission to use (where not already granted under a licence) please go to http://group.bmj.com/group/rights-licensing/ permissions 